\title{
ДОСЛІДЖЕННЯ ОБЛАСТІ НЕСУЧОЇ ЗДАТНОСТІ ТОНКОСТІННИХ СТЕРЖНЕВИХ ЕЛЕМЕНТІВ ІЗ ХОЛОДНОГНУТИХ ПРОФІЛІВ
}

\author{
Перельмутер А. В., д.т.н., с.н.с., \\ НПО «СКАД Софт»» \\ avp@scadsoft.com \\ Юрченко В. В., к.т.н., доцент, \\ Киїський національний університет будівниџтва та архітектури \\ vitalina@ scadsoft.com, ORCID: 0000-0003-4513-809X
}

\begin{abstract}
Анотація. У статті розглядаються області несучих здатностей для поперечних перерізів тонкостінних стержневих елементів конструкцій із холодногнутих профілів. Звертається увага на важливу властивість області несучої здатності - iï випуклість. Представлено алгоритм автоматизованої побудови областей несучої здатності для перерізів стержневих елементів конструкцій, який реалізований в обчислювальному комплексі SCAD Office.

Виконані дослідження області несучої здатності для перерізів стержневих конструкцій із холодногнутих профілів слугують засобом критичного аналізу вимог норм проектування, що регламентую розрахунок та проектування несучих елементів конструкцій із холодногнутих профілів. Виявлена невипуклість та стрибкоподібна зміна границі області несучої здатності, що обумовлена неузгодженостями окремих положень розглядуваного нормативного документу.
\end{abstract}

Ключові слова: несуча здатність, тонкостінні стержневі системи, холодногнутий профіль, область несучої здатності

Введення. Сьогодні на український ринок металоконструкцій активно імпортуються різноманітні конструктивні системи із тонкостінних холодногнутих профілів, які знайшли широке застосування у будівельній індустрії. Впровадження у практику будівництва конструкцій із тонкостінних холодногнутих профілів $\epsilon$ актуальним та економічно обгрунтованим [1].

Питання розрахунку та проектування тонкостінних стержневих елементів із холодногнутих профілів відображені у європейських нормах проектування [2, 3]. Широке використання конструкцій із тонкостінних холодногнутих профілів вітчизняного виробництва затримується передусім недосконалістю нормативної бази та недостатністю вітчизняного досвіду економічного та надійного проектування таких конструкцій.

У системі SCAD Office широко використовується побудова областей несучої здатності, які відрізняються тим, що враховують повний набір нормативних вимог, що висуваються до розглядуваного класу конструкцій. Форма області несучої здатності перерізу, а також характер іiі границь дозволяє у багатьох випадках детально проаналізувати вимоги норм проектування. Аналіз границь області дозволяє виявити протиріччя окремих положень розглядуваного нормативного документу, а також погане стикування (не гладке спряження) окремих його положень.

Мета та завдання. У зв'язку з імплементацією на території України норм проектування $[2,3]$, що регламентують розрахунок і проектування несучих елементів конструкцій із холодногнутих профілів, метою досліджень $є$ детальний аналіз та перевірка несуперечності, узгодженості та повноти цих нормативних вимог. Досягнення поставленої мети здійснюється на основі вирішення таких задач досліджень: побудувати області несучої здатності перерізів стержневих елементів конструкцій із тонкостінних холодногнутих профілів; дослідити форму побудованих областей та характер ії границь.

Матеріали та методика дослідження. Нормативні вимоги щодо забезпечення необхідної несучої здатності стержневих елементів із холодногнутих профілів, що висуваються до деякого розрахункового перерізу конструкції, можна записати у вигляді 
деякого набору обмежень-нерівностей, які описують несучу здатність досліджуваного класу конструкцій щодо втрати міцності, а також загальної та місцевої стійкості:

$$
\boldsymbol{\Phi}\left(\vec{S}_{j m k}\right) \leq 1 .
$$

Кожне $з$ обмежень (1) функціонально залежить від значень внутрішніх зусиль $\vec{S}_{j m k}=\left\{N_{j m k}, M_{y, j m k}, Q_{z, j m k}\right\}$, що виникають у $m$-му розрахунковому перерізі $j$-го стержневого елементу конструкції при дії $k$-ої розрахункової комбінації навантажень:

$$
\boldsymbol{\Phi}\left(\vec{S}_{j m k}\right)=\left\{\xi_{l}=\phi_{l}\left(N_{j m k}, M_{y, j m k}, Q_{z, j m k}\right) \leq 1\right\}, \imath=\overline{1, N_{L B C}} ;
$$

тут $N_{L B C}$ - загальна кількість обмежень-нерівностей, що визначають несучу здатність стержневих елементів із холодногнутих профілів щодо втрати міцності, а також загальної та місцевої стійкості. Числове значення лівої частини обмежень-нерівностей $\xi_{l}=\phi_{l}\left(N_{j m k}, M_{y, j m k}, Q_{z, j m k}\right)$ будемо називати коефіцієнтом використання обмеження.

Кожне $з$ обмежень $\phi_{t}\left(N_{j m k}, M_{y, j m k}, Q_{z, j m k}\right)$ (2) визначає деяку область у просторі внутрішніх зусиль (у нашому випадку тривимірному), а перетин усіх нерівностей сукупності нормативних обмежень $\boldsymbol{\Phi}\left(\vec{S}_{j m k}\right)$ утворює область несучої здатності перерізу $\boldsymbol{\Omega}_{\mathrm{s}}$ у термінах розглядуваних норм проектування (рис. 1). Для кожної точки області несучої здатності перерізу максимальний коефіцієнт використання обмеження складає $\xi_{\max }=\max \left\{\xi_{l} \mid \imath=\overline{1, N_{L B C}}\right\} \leq 1$.

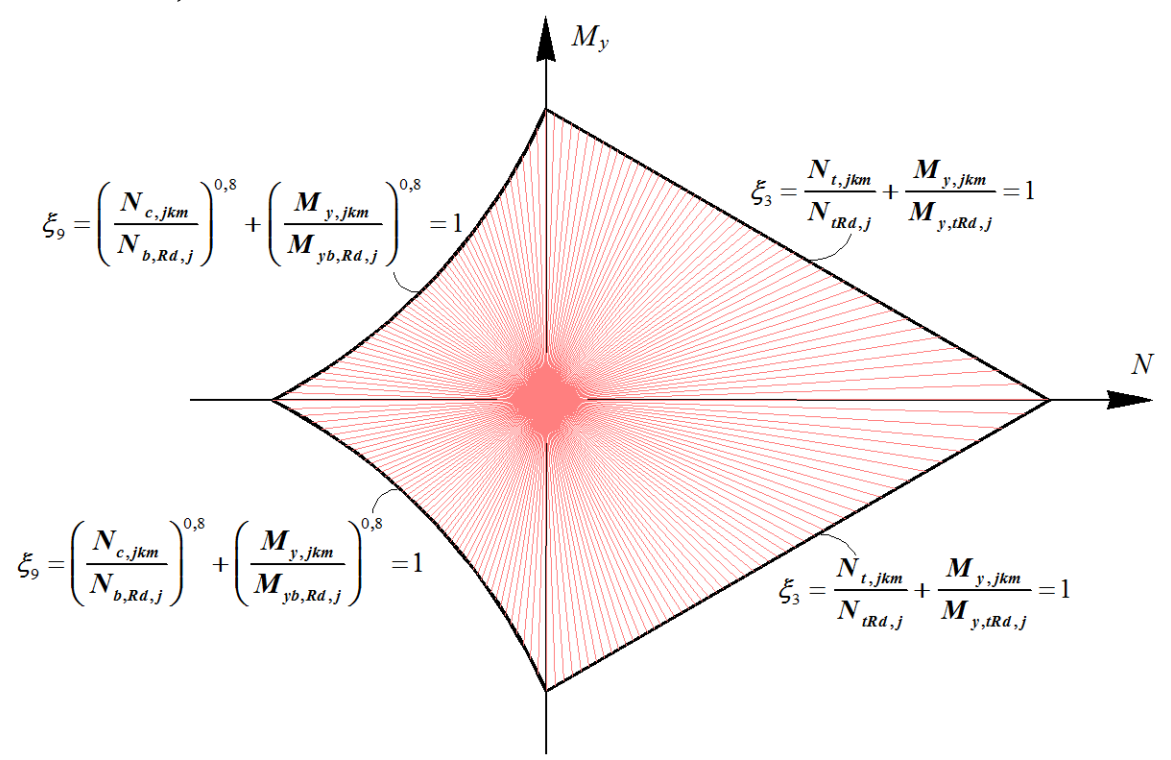

Рис. 1. Формування області несучої здатності перерізу у двовимірному просторі внутрішніх зусиль (приклад)

Однією із найважливіших властивостей області несучої здатності є їі випуклість. Наголосимо, що саме випуклість області несучої здатності перерізу дає нам право обмежитись у лінійному розрахунку перевірками такого перерізу на дію лише тих поєднань внутрішніх зусиль у перерізі, для яких характерними $є$ екстремальні (мінімальні або максимальні) значення [4].

Форма області несучої здатності $\boldsymbol{\Omega}_{\mathbf{s}}$ цілком та повністю визначається системою обмежень (1), що регламентуються вимогами норм на проектування даного класу конструкцій. При побудові області несучої здатності $\boldsymbol{\Omega}_{\mathbf{s}}$ окрім обмежень міцності, розглядаються також обмеження загальної та місцевої стійкості, які можуть спричинити невипуклу форму області несучої здатності перерізів із холодногнутих профілів. Це зумовлює необхідність виконання подальших досліджень форми області несучої здатності 
перерізів стержневих елементів конструкцій із холодногнутих профілів.

Для стержневих елементів конструкцій із холодногнутих профілів, у перерізах яких під навантаженням можуть виникати трійка внутрішніх зусиль (поздовжня сила, згинальний момент та відповідна поперечна сила), область несучої здатності представляє собою тривимірну геометричну фігуру. Найбільш наглядно відобразити область несучої здатності перерізів можна за допомогою іiі ортогонального проеціювання на деяку площину, що визначається парою внутрішніх зусиль.

У середовищі SCAD Office широко використовується побудова областей несучої здатності, що відрізняються врахуванням повного набору нормативних вимог (обмежень міцності, загальної та місцевої стійкості), що висуваються до того чи іншого елемента конструкції, для якого будується область.

Побудова двовимірної проекції області несучої здатності перерізу виконується за наведеним нижче алгоритмом. Обирається пара внутрішніх зусиль (наприклад, пара «поздовжня сила $N$ - згинальний момент $M_{y}$ ), у системі координат якої буде побудована ортогональна проекція області несучої здатності. Решта внутрішніх зусиль у перерізі фіксуються на деякому рівні (задаються користувачем або приймають нульові значення). При деякому фіксованому значенні відношення згинального моменту $M_{y}$ до поздовжньої сили $N$ (фактично, на промені $\mathbf{e}_{\alpha}$, випущеному із початку координат під кутом $\alpha=\operatorname{arctg}\left(M_{y} / N\right)$ до осі абсцис, виміряному проти годинникової стрілки) вишукується точка, відстань до якої від початку координат є найбільшою та для якої ще виконуються нормативні обмеження (1). Для такої точки деяке (або деякі) обмеження із сукупності Ф приймає граничне значення $\phi_{t}\left(N_{j m k}, M_{y, j m k}, Q_{z, j m k}\right)=1$, тому ця точка належить границі двовимірної ортогональної проекції області несучої здатності перерізу.

Уся границя області несучої здатності будується шляхом перебору кутів $\alpha$ (із кроком $1^{\circ}$ ), що визначають положення променів $\mathbf{e}_{\alpha}$. Таким способом будуються двовимірні ортогональні проекції області несучої здатності для будь-якої заданої пари внутрішніх зусиль $\left(N-Q_{z}, M_{y}-Q_{z}\right.$ тощо).

Результати досліджень. Автоматизована побудова області несучої здатності перерізів стержневих елементів із холодногнутих профілів забезпечує можливість дослідити форму області, а також характер іiї границь, що дозволяє детально проаналізувати нормативні вимоги, що висуваються до розглядуваного класу конструкцій. Аналіз границь області несучої здатності перерізів стержневих елементів із холодногнутих профілів дозволяє, зокрема, виконати перевірку несуперечності, узгодженості та повноти системи обмежень (1). При цьому легко виявляються погане стикування (не гладке спряження) окремих нерівностей системи обмежень.

Побудуємо ортогональну проекцію області несучої здатності в системі координат «поздовжня сила $N$ - згинальний момент $M$ » для подвійно симетричного поперечного перерізу, що складається із двох холодногнутих швелерних профілів з висотою профілю $h=300$ мм та шириною полички $b=150$ мм, виконаних із сталі S355N EN 10025 з межею текучості $f_{y b}=355 \mathrm{MПа} \mathrm{та} \mathrm{межею} \mathrm{міцності} f_{u}=470$ МПа. Розрахункова довжина стержневого елемента в обох головних площинах інерції складає 6,0 м, часткові коефіцієнти надійності $\gamma_{M 0}=1, \gamma_{M 1}=1$.

Область несучої здатності $\boldsymbol{\Omega}_{\mathbf{s}}$ такого перерізу відповідно до нормативних вимог $[2,3]$ наведена на рис. 2.

Границі області несучої здатності $G O P B$ та $H Q R C$ відповідають обмеженням міцності при одночасній дії зусилля розтягу та згинального моменту, сформульованим залежно від геометричних характеристик редукованого перерізу, тобто коли переріз зазнав втрати місцевої стійкості. Як видно із рис. 2 на ділянках GOP і $H Q R$ границі побудованої області при збільшенні поздовжньої сили розтягу несуча здатність перерізу збільшується, що пояснюється одночасним збільшенням геометричних характеристик редукованого перерізу за рахунок 
зменшення розмірів (ширини) тих ділянок перерізу, що втрачають місцеву стійкість.

Границі області несучої здатності $A F$ і $D F$ відповідають тим самим обмеженням міцності при одночасній дії зусилля розтягу та згинального моменту, але сформульованим вже залежно від геометричних характеристик перерізу брутто, тобто коли переріз не зазнав втрати місцевої стійкості або втрати стійкості форми перерізу.

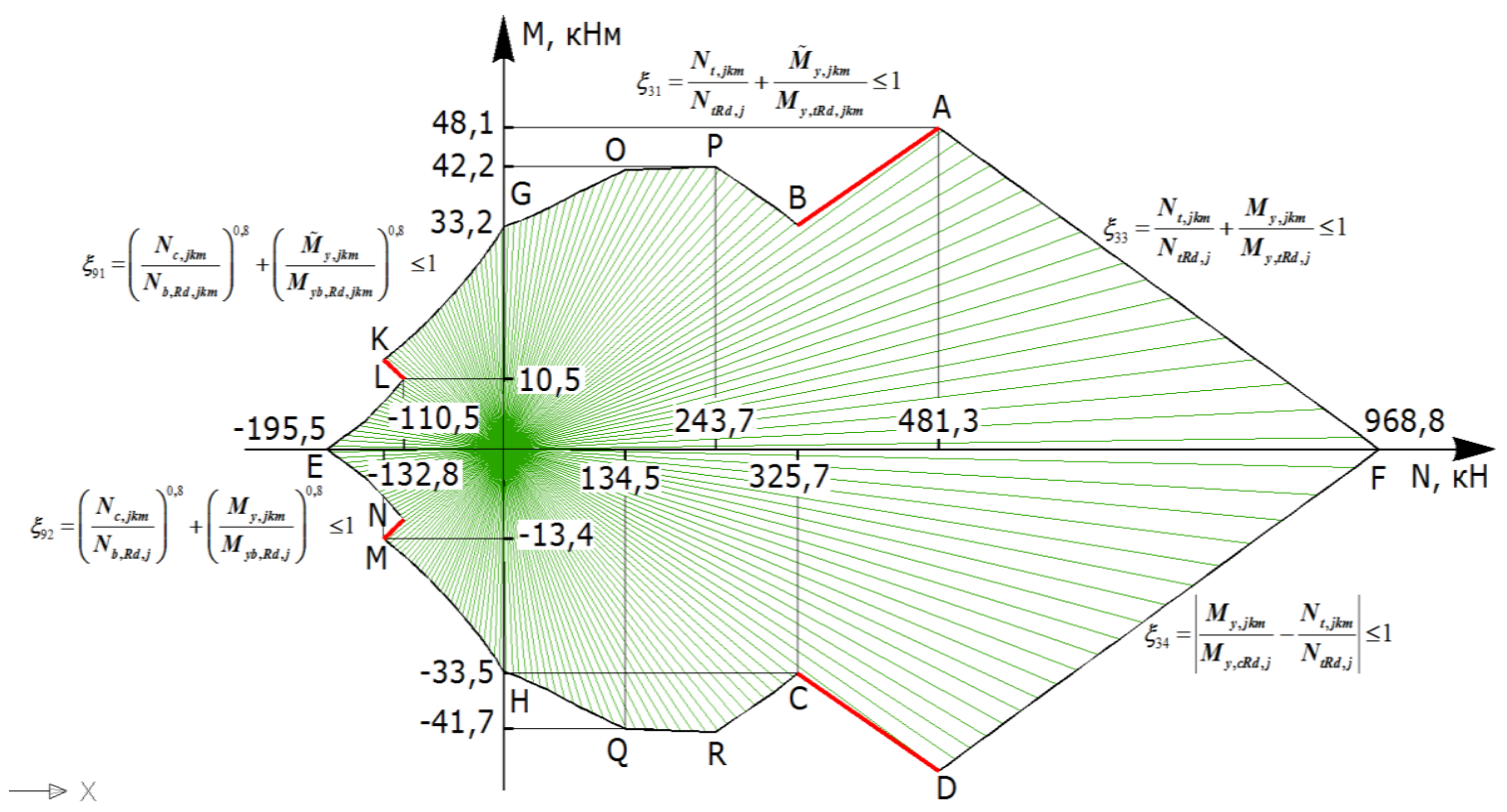

Рис. 2. Ортогональна проекція області несучої здатності $\boldsymbol{\Omega}_{\mathrm{s}}$ складеного перерізу із двох холодногнутих швелерних профілів в координатній системі «поздовжнє зусилля $N$ - згинальний момент $M$ »

При напруженому стані, коли у перерізі діють тільки нормальні напруження розтягу, розглядуваний переріз не зазнає втрати місцевої стійкості. У цьому випадку обмеження міцності при одночасній дії поздовжньої сили та згинального моменту формулюються залежно від геометричних характеристик перерізу брутто. Їм відповідають границі $A F$ і $D F$ області несучої здатності $\boldsymbol{\Omega}_{\mathrm{s}}$.

Стрибки $A B$ і $C D$ області несучої здатності відповідають переходу перерізу у закритичну стадію роботи, що характеризується настанням явища втрати місцевої стійкості елементів перерізу та супроводжується переходом від обмежень міцності, сформульованих для редукованого поперечного перерізу, до обмежень міцності, сформульованих для поперечного перерізу брутто.

Границі області несучої здатності $G K, H M, E L, E N$ відповідають обмеженню загальної стійкості при одночасній дії поздовжньої сили стику та згинального моменту математичної моделі, сформульованому залежно від геометричних характеристик редукованого поперечного перерізу для випадку, коли переріз зазнав втрати місцевої стійкості. Стрибки $K L$ і $M N$ області відповідають коригуванню згинального моменту за рахунок зміщення центру ваги редукованого поперечного перерізу по відношенню до центру ваги поперечного перерізу брутто. Оскільки таке коригування виконують лише за умови, якщо його результатом буде збільшення значення згинального моменту, i не виконують у протилежному випадку, отримаємо стрибкоподібне зменшення несучої здатності на області несучої здатності $\boldsymbol{\Omega}_{\mathbf{s}}$.

Відсутність властивості випуклості області несучої здатності для перерізів стержневих елементів досліджуваного класу конструкцій може призвести до неприємних наслідків, пов'язаних із тією обставиною, що за традицією оцінюючі найнесприятливіші поєднання внутрішніх зусиль, інженери або взагалі не розглядають деякі навантаження та впливи (у тому випадку, коли вони чинять розвантажувальну дію), або враховують їх повністю (із 
екстремальним або розрахунковим значенням навантаження). Це правило $є$ цілком справедливим для випуклої області несучої здатності, тоді як для не випуклої області невигідним може виявитись поєднання внутрішніх зусиль 3 проміжними (не екстремальними) значеннями.

Проілюструємо сказане на прикладі. Розглянемо отриману невипуклу область несучої здатності (рис. 2) складеного перерізу із двох холодногнутих швелерних профілів при дії на конструкцію двох незалежних навантажень Р і $\Theta$ (рис. 3).

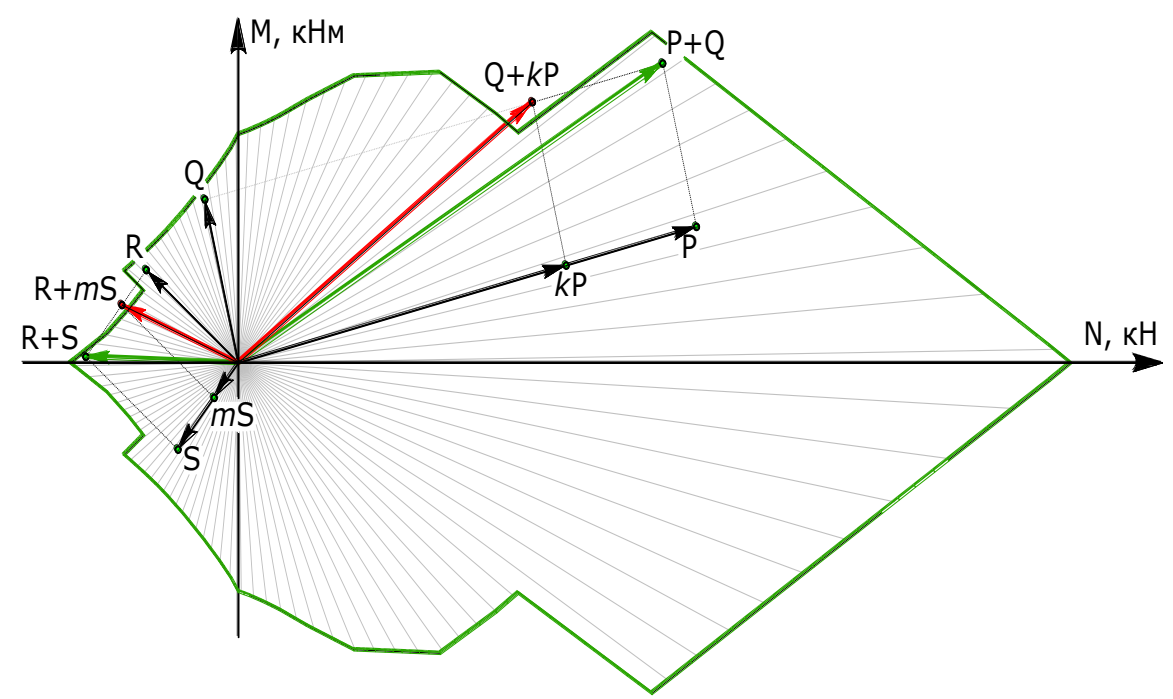

Рис. 3. Перевірка несучої здатності перерізу на дію комбінацій навантажень 3 «не екстремальними» значеннями

Точка $P$ на рис. 3 відповідає парі внутрішніх зусиль (поздовжній силі $N$ та згинальному моменту $M$ ), що виникають у розглядуваному перерізі при дії навантаження $\mathbf{P}$, а точка $Q-$ від дії навантаження $\boldsymbol{\Theta}$. 3 рис. 3 не важко побачити, що нормативні вимоги виконуються як при перевірці перерізу на дію кожного навантаження $\mathbf{P}$ і $\boldsymbol{\Theta}$ окремо, а також при перевірці перерізу на дію їх повної суми $(\mathbf{P}+\boldsymbol{\Theta})$, оскільки точки $P, Q$, а також точка $P+Q$ належать області несучої здатності перерізу. Але при дії «неповної» лінійної комбінації навантажень $(\boldsymbol{\Theta}+k \mathbf{P})$, коли $k<1$, нормативні вимоги порушуються, оскільки у розглядуваному перерізі при дії $\boldsymbol{\Theta}+k \mathbf{P}$ виникає пара внутрішніх зусиль, що відповідає точці $Q+k P$ на рис. 3 , яка не належить області його несучої здатності.

Небезпеки, пов'язані з невипуклістю області несучої здатності, вказують на необхідність виконання аналізу близькості реальної сукупності поєднань розрахункових внутрішніх зусиль до тієї або тих ділянки області $\mathbf{\Omega}_{\mathrm{s}}$, де проявляються властивості невипуклості.

Практично такий аналіз може бути реалізований із використанням додаткового інструментарію, який надається компонентами SCAD Office. Цей інструментарій забезпечує можливість відобразити на області несучій здатності розглядуваного перерізу усю множину варіантів поєднань внутрішніх зусиль, на дію яких переріз підлягає перевірці, у вигляді набору точок, кожна 3 яких відповідає одному із таких варіантів (рис. 4). Також демонструється випукла оболонка цих точок, яка охоплює множину поєднань внутрішніх зусиль, що $є$ лінійними комбінаціями вихідних варіантів поєднань внутрішніх зусиль. У випадку, коли зазначена випукла оболонка не виходить за границі області несучої здатності перерізу (рис. 4, a), можна гарантувати, що й різноманітні комбінації поєднань вихідних варіантів внутрішніх зусиль не будуть небезпечними. В іншому випадку, коли випукла оболонка виходить за границі області несучої здатності перерізу (рис. 4, б), тоді комбінація внутрішніх зусиль зі значеннями, що не перевищують розрахункові граничні, може виявитися більш несприятливою. 


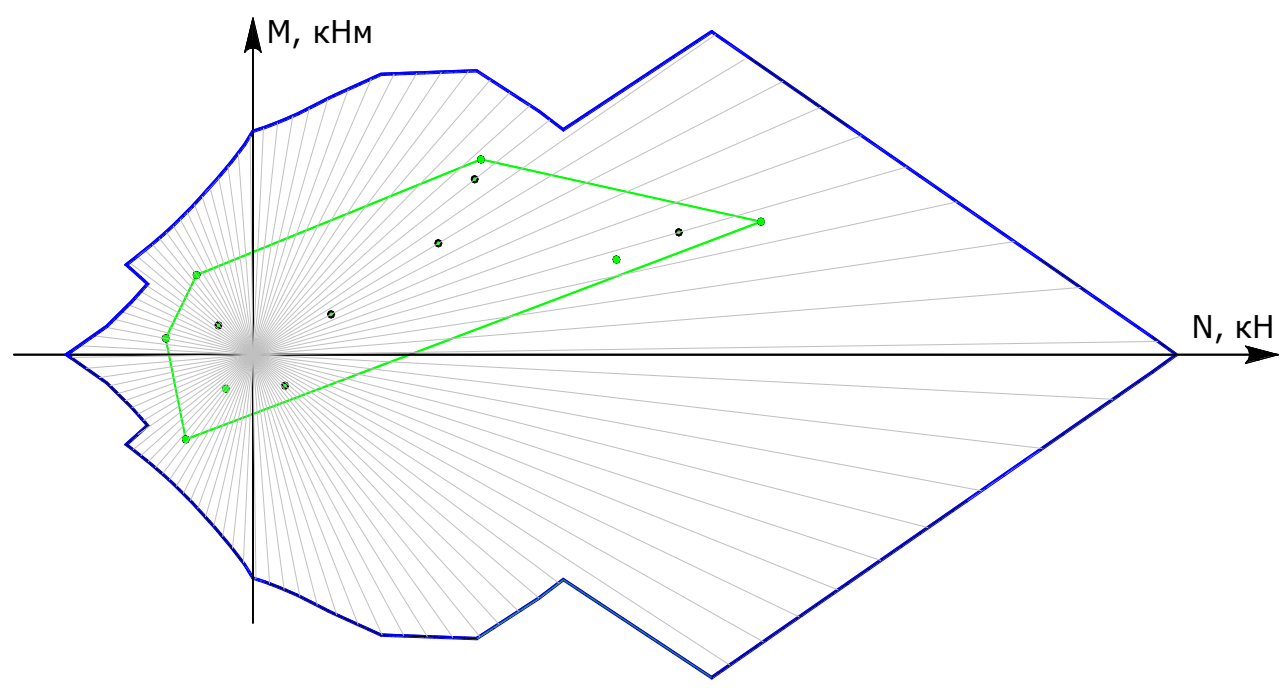

a)

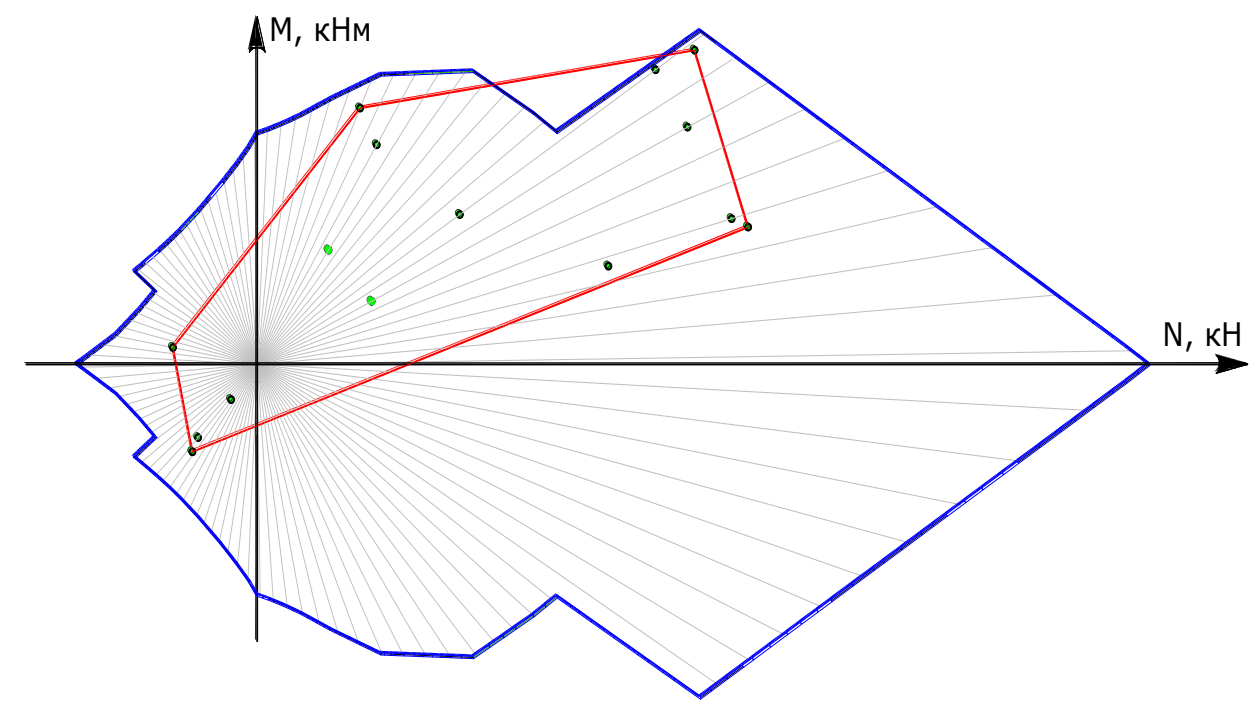

б)

Рис. 4. Задані комбінації навантажень та їх випукла оболонка, суміщена з областю несучої здатності перерізу стержневого елемента із холодногнутих профілів

Висновки. Виконані дослідження форми області несучої здатності перерізів стержневих елементів конструкцій із холодногнутих профілів засвідчили іiі невипуклість. Стрибкоподібна зміна несучої здатності стержневих елементів конструкцій із холодногнутих профілів характерна при переході поперечних перерізів у закритичну стадію роботи, що характеризується втратою місцевої стійкості або втратою стійкості форми перерізу. Окрім того, стрибкоподібна зміна несучої здатності таких елементів також характерна при коригуванні згинального моменту за рахунок зміщення центру ваги редукованого поперечного перерізу по відношенню до центру ваги поперечного перерізу брутто.

\section{Література}

1. Бєлов I. Д. Розробка та впровадження ефективних конструкцій будівель із тонкостінних холодногнутих профілів: сучасний стан проблеми та програма досліджень / І. Д. Бєлов, В.В.Юрченко // Збірник наукових праць «Ресурсоекономні матеріали, конструкції, будівлі та споруди», Вип. 20. - Рівне, 2010. - С. 364 - 369.

2. ДСТУ-Н Б ЕN 1993-1-3:2012 ЄВРОКОД 3. Проектування сталевих конструкцій. Частина 1-3. Загальні правила. Додаткові правила для холодноформованих елементів i 
профільованих листів (EN 1993-1-3:2006, IDT). - Київ, Мінрегіонбуд України, 2012. - 220 с.

3. ДСТУ-Н Б ЕN 1993-1-5:2012 СВРОКОД 3: Проектування сталевих конструкцій. Частина 1-5. Пластинчасті конструктивні елементи (EN 1993-1-5:2005, IDT). - Київ, Мінрегіонбуд України, 2012. - 97 с.

4. Gavrilenko I. S. Load-bearing capacity as an interactive analysis tool in SCAD Office / I. S. Gavrilenko, S. V. Girenko, A. V. Perelmuter, M. A. Perelmuter, V. V. Yurchenko // Proceedings of the METNET Seminar 2017 in Cottbus / Eds. by Kuldeep Virdi \& Lauri Tenhunen. - Häme University of Applied Science, 2018. - pp. 112 - 127.

\title{
References
}

[1] I.D. Bielov I.D., V.V. Yurchenko, "Rozrobka ta vprovadzhennja efektyvnyh konstrukcij budivel iz tonkostinnyh holodnognutyh profiliv: suchasnyj stan problemy ta programa doslidzhen", Zbirnyk naukovyh prac "Resursoekonomni materially, konstrukciji, budivli ta sporudy, Rivne, vol. 20, pp. 364 - 369, 2010.

[2] DSTU-N B EN 1993-1-3:2012 EUROKOD 3. Proektuvannya stalevyh konstruktsiy. Chastyna 1-3. Zagalni pravyla. Dodatkovi pravyla dlya holodnoformovanyh elementiv i profilovanih lystiv (EN 1993-1-3:2006, IDT). Kyiv, Minregionbud Ukrainy, 2012.

[3] DSTU-N B EN 1993-1-5:2012 EUROKOD 3: Proektuvannya stalevyh konstruktsiy. Chastyna 1-5. Plastinchasti konstruktyvni elementy (EN 1993-1-5:2005, IDT). Kyiv, Minregionbud Ukrainy, 2012.

[4] I. S. Gavrilenko, S. V. Girenko, A. V. Perelmuter, M. A. Perelmuter, V. V. Yurchenko, "Loadbearing capacity as an interactive analysis tool in SCAD Office", proceedings of the METNET Seminar 2017 in Cottbus, Häme University of Applied Science, pp. 112 - 127, 2018.

\section{ИССЛЕДОВАНИЕ ОБЛАСТИ НЕСУЩЕЙ СПОСОБНОСТИ ТОНКОСТЕННЫХ СТЕРЖНЕВЫХ ЭЛЕМЕНТОВ ИЗ ХОЛОДНОГНУТЫХ ПРОФИЛЕЙ}

\author{
Перельмутер А. В., Д.т.н., с.н.с. \\ НПО «СКАД Софm» \\ avp@scadsoft.com
}

Юрченко В. В., к.т.н., доцент Киевский национальный университет строительства и архитектуры vitalina@scadsoft.com, ORCID: 0000-0003-4513-809X

Аннотация. В статье рассматриваются области несущей способности для поперечных сечений тонкостенных стержневых элементов конструкций из холодногнутых профилей. Обращается внимание на важную особенность области несущей способности - ее выпуклость. В статье представлен случай, когда комбинация внутренних усилий со значениями, которые не являются расчетными для первой группы предельных состояний, может оказаться более неблагоприятной для невыпуклой области несущей способности стержневых элементов из холодногнутых профилей.

Представлен алгоритм автоматизированного построения областей несущей способности для сечений стержневых элементов конструкций и его программная реализация в вычислительном комплексе SCAD Office. Построение области несущей способности поперечного сечения, совмещенное с выпуклой оболочкой заданных комбинаций внутренних усилий, является гибким инструментом для анализа условий загружения рассматриваемой конструкции. В случае, когда выпуклая оболочка внутренних усилий не выход за границы области несущей способности сечения, можно гарантировать, что и различные комбинации сочетаний исходных вариантов внутренних усилий не будут неблагоприятными.

Изучение области несущей способности для сечений стержневых конструкций из холодногнутых профилей служит способом критического анализа требований норм, 
регламентирующих расчет и проектирование рассматриваемого класса конструкций. В результате выполненных исследований выявлена не выпуклость и скачкообразное изменение границ области несущей способности поперечных сечений стержневых элементов из холодногнутых профилей, обусловленное несогласованностью отдельных положений нормативного документа. Такой характер области наблюдается при переходе от одной расчетной ситуации (закритическая работа элемента конструкции после достижения явления местной потери устойчивости или потери устойчивости формы сечения) к другой (работа в границах упругих деформаций стали). Кроме того, скачкообразное изменение несущей способности также характерно при корректировке изгибающего момента за счет смещения центра масс редуцированного поперечного сечения по отношению к центру масс поперечного сечения брутто.

Ключевые слова: несущая способность, тонкостенные стержневые системы, холодногнутый профиль, область несущей способности.

\title{
LOAD-BEARING CAPACITY REGION ANALYSIS OF THIN-WALLED STRUCTURAL MEMBERS FROM COLD-FORMED PROFILES
}

\author{
Perelmuter A. V., Doctor of Engineering, Senior Scientist, \\ $N P O \ll S C A D$ Soft $»$, \\ avp@scadsoft.com \\ Yurchenko V. V., PhD, Associate Professor, \\ Kyiv National University of Construction and Architecture \\ vitalina@scadsoft.com, ORCID: 0000-0003-4513-809X
}

\begin{abstract}
Load-bearing capacity region for cross-sections of thin-walled cold-formed structural members in terms of design codes has been considered. The main attention has been paid to an important property of the region - its convexity. The paper presents a case when internal forces with not ultimate design values can be unfavorable for a non-convex load-bearing capacity region of the cold-formed structural members.

Algorithm for automatic generation of load-bearing capacity regions for structural sections has been presented and implemented in SCAD Office software package. The program also enables to show the position of points corresponding to the specified internal forces and to plot a convex shell on the basis of these points thus bounding the part of the load-bearing capacity region, which corresponds to any linear combination of design internal forces in the considered cross-section or structural joint. Construction of load-bearing capacity regions of a section combined with a convex shell of specified internal forces is flexile tool for analysis of load conditions. In the case when the convex shell of loadings does not leave the load-bearing capacity area of the section, it can be ensured that the various loadings combined from the initial ones are not unfavorable.

Load-bearing capacity region study has been performed for cross-sections of cold-formed structural members as the means for critical analysis of code-based requirements and regulations used for verifications of considered type of structures. Non-convexity and abrupt change of load-bearing capacity region occur here, which are caused by some inconsistencies with the code requirements. In particular, these effects arise due to some kinds of strict logical transitions from one design situation (post-critical buckling behavior of the structural member based on local buckling and/or distortional buckling) to another (elastic behavior of the structural member). Besides, abrupt change of loadbearing capacity region also occurs when correcting design bending moment due to the shift of the effective cross-section centroidal axes relating to the gross cross-section centroidal axes.

Key words: load-bearing capacity, thin-walled structural members, cold-formed profile, loadbearing capacity region.
\end{abstract}

